\title{
Review Article \\ The Janus Face of Stress on Reproduction: From Health to Disease
}

\author{
Dóra Zelena \\ Hungarian Academy of Sciences, Institute of Experimental Medicine, Szigony 43, Budapest 1083, Hungary \\ Correspondence should be addressed to Dóra Zelena; zelena.dora@koki.mta.hu
}

Received 17 December 2014; Revised 17 March 2015; Accepted 20 March 2015

Academic Editor: Sabrina Corbetta

Copyright (C) 2015 Dóra Zelena. This is an open access article distributed under the Creative Commons Attribution License, which permits unrestricted use, distribution, and reproduction in any medium, provided the original work is properly cited.

\begin{abstract}
Parenthood is a fundamental feature of all known life. However, infertility has been recognized as a public health issue worldwide. But even when the offspring are conceived, in utero problems can lead to immediate (abortion), early (birth), and late (adulthood) consequences. One of the most studied factors is stress. However, stress response is, per se, of adaptive nature allowing the organism to cope with challenges. Stressors lead to deterioration if one is faced with too long lasting, too many, and seemingly unsolvable situations. In stress adaptation the hypothalamus-pituitary-adrenocortical axis and the resulting glucocorticoid elevation are one of the most important mechanisms. At cellular level stress can be defined as an unbalance between production of free radicals and antioxidant defenses. Oxidative stress is widely accepted as an important pathogenic mechanism in different diseases including infertility. On the other hand, the goal of free radical production is to protect the cells from infectious entities. This review aims to summarize the negative and positive influence of stress on reproduction as a process leading to healthy progeny. Special emphasis was given to the balance at the level of the organism and cells.
\end{abstract}

\section{Introduction}

Parenthood is one of the most universally desired goals of adulthood in all species [1]. However, among humans not all couples who desire a child will achieve one spontaneously. Although global infertility prevalence rates are difficult to determine due to the presence of both male and female factors [2], infertility has been recognized as a public health issue worldwide by the World Health Organization [3]. One in every four couples in developing countries had been found to be affected by infertility. Around $50 \%$ of these cases are due to males, while the other half is due to female factors $[4,5]$. Thus, the burden remains high. For better understanding of the biological processes and for developing new treatment strategies animal models are indispensable. Moreover, there is an economic interest due to livestock and plant infertility.

Reproduction. Reproduction is a fundamental feature of all known life; each individual organism exists as the result of reproduction and its main goal is to reproduce its gens
[6]. In asexual reproduction an individual can reproduce without involvement of another individual of that species [7]. Sexual reproduction typically requires the involvement of two individuals or gametes. There is a wide range of reproductive strategies [8]. Some animals such as the human do not reach sexual maturity for many years after birth and even then produce few offspring ( $k$-strategy). For example, elephants have one baby about three years apart, and the whole group looks after the youngsters. Because they ensure the survival of a good percentage of their young, elephants do not need to produce many offspring to hold their numbers close to constant. Other species reproduce quickly; however, under normal circumstances, most offspring do not survive to adulthood ( $r$-strategy). Frogs are a good example as they lay many eggs and leave them in the water to hatch into tadpoles. Some of the eggs and many of the little tadpoles as well as developed frogs get eaten; thus, if one frog from a hundred eggs lives to be a parent, his/her survival is really outstanding. However frogs survive because of the many eggs. 
In a wider view reproduction is a process leading to healthy progeny. This process can be influenced by internal and external factors. First of all several factors have an impact on fertility and mating ability of the individuals. But even when the offspring are conceived, in utero problems can lead to immediate (abortion), early (detectable at birth, e.g., preterm birth, low birth weight, and malformations), and late consequences (detectable later in life and might be only changes in vulnerability) [9]. The "developmental origins of health and disease" concept says that the risk of developing some chronic diseases in adulthood is influenced by environmental factors acting during the periconceptual, fetal, and infant phases of early life [10].

Nowadays human beings are challenged by changing in mother-child relationship and social models of the extended family [11]. The accelerated pace of life and unpredictable environmental changes are added to the above factors. All of these factors are, actually, chronic stressors, which we have to deal with and they influence the reproduction.

\section{Stress}

In the Body. Numerous health experts say that the number one killer on the planet is stress. On the other hand the father of stress concept, Hans Selye, considered stress the "spice of life" [12]. As such, he felt it was neither advantageous nor even possible to eliminate it from life. Instead, the challenge is to contain any stress and channel it into feelings of mastery.

We have to take into consideration a number of factors contributing to the qualitative nature of the stress response such as the intensity (high or low) and duration (acute or chronic) of stressors, the individual's ability to initiate an adaptive response, and the phase of the life when the stressor event occurs [13]. When we can cope with the challenges, then we can become stronger (Figure 1). Thus, stress response is, per se, of adaptive nature as it allows the organism to cope with stressful challenges, no matter of what nature, and to maintain or restore body homeostasis. This is considered to be eustress, which has also been positively correlated with life satisfaction and well-being. On the contrary, when a person is unable to adapt to the stressors, they will induce maladaptive behaviors. We can call this state distress. We have to be also aware that the complete lack of stimuli is also harmful. Thus, although it is important to minimize your distress, yet at the same time you have to maximize your eustress by optimizing the amount of stimuli.

During stress several systems are activated in the body; however, according to Selye, the hypothalamus-pituitaryadrenocortical (HPA) axis, as well as the resulting glucocorticoid (GC) elevation, is the most important one (Figure 2). As a final common pathway to different kind of stimuli corticotropin-releasing hormone $(\mathrm{CRH})$ and arginine vasopressin (AVP) are released from the parvocellular cells of the nucleus paraventricularis hypothalami (PVN) to the long portal vessels of the median eminence [14]. They reach the anterior lobe of the pituitary through these vessels and stimulate the synthesis and release of adrenocorticotropin (ACTH) from the adenohypophysis. ACTH reaches the adrenal gland

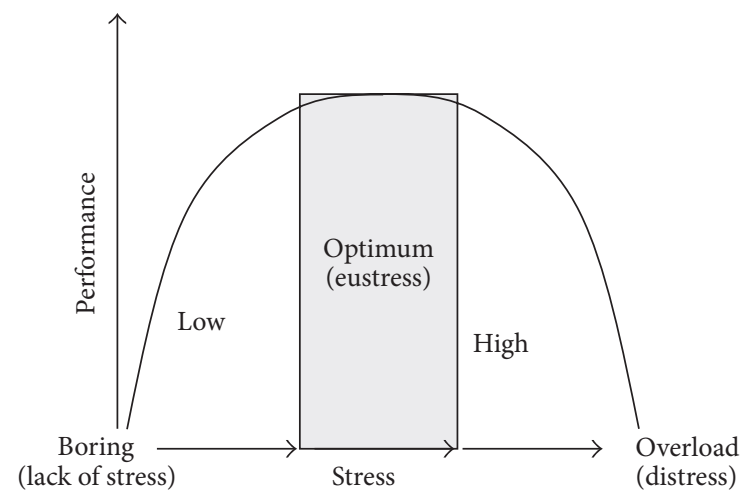

FIGURE 1: Stress in the body: an optimal level of stress (called eustress) is required for the best performance. Not only too much, but also too little stimuli are harmful.

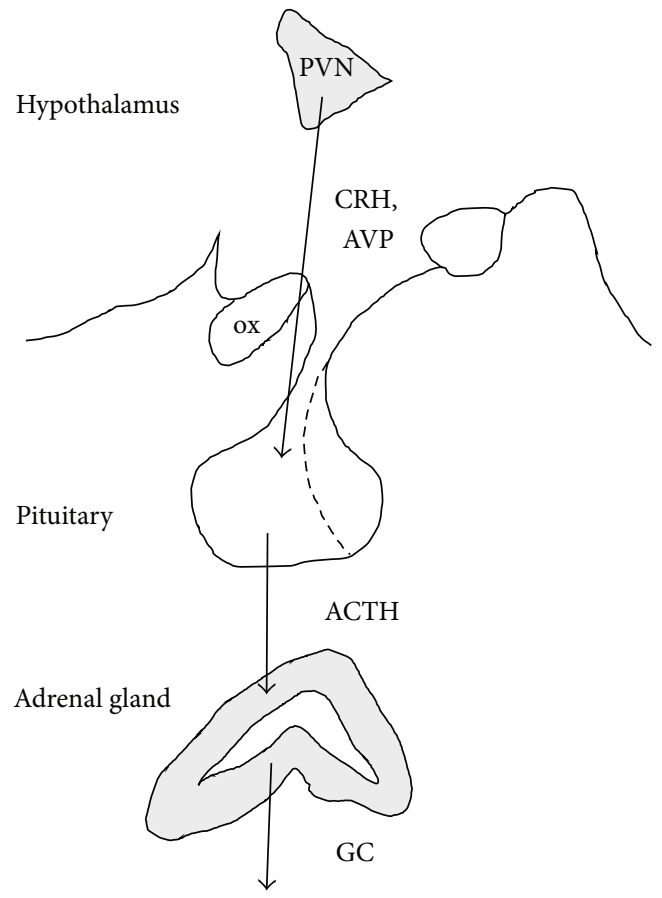

The effect of chronically enhanced GC on reproduction is as follows: epigenetic changes, reduced weight of reproductive organs, shift in puberty onset, gonad hormone dysfunction, miscarriage, preterm labour, and poor immediate and late outcomes in offspring

FIgURE 2: The stress axis: the activation of the hypothalamopituitary-adrenocortical axis is fundamental for adaptation. PVN: nucleus paraventricularis hypothalami, ox: optic chiasm, CRH: corticotropin-releasing hormone, AVP: arginine vasopressin, ACTH: adrenocorticotropin, and GC: glucocorticoids, in rodents corticosterone.

through the general circulation and releases GCs (mainly cortisol in human and corticosterone in rodents) from the zona fasciculata of the adrenal cortex. The release of GCs is an adaptive response with an ultimate goal to maintain homeostasis. HPA axis activation favors energy mobilization, cardiac output, and sharpened cognition over growth, cellular immunity, and reproduction. Thus, at high circulating levels 


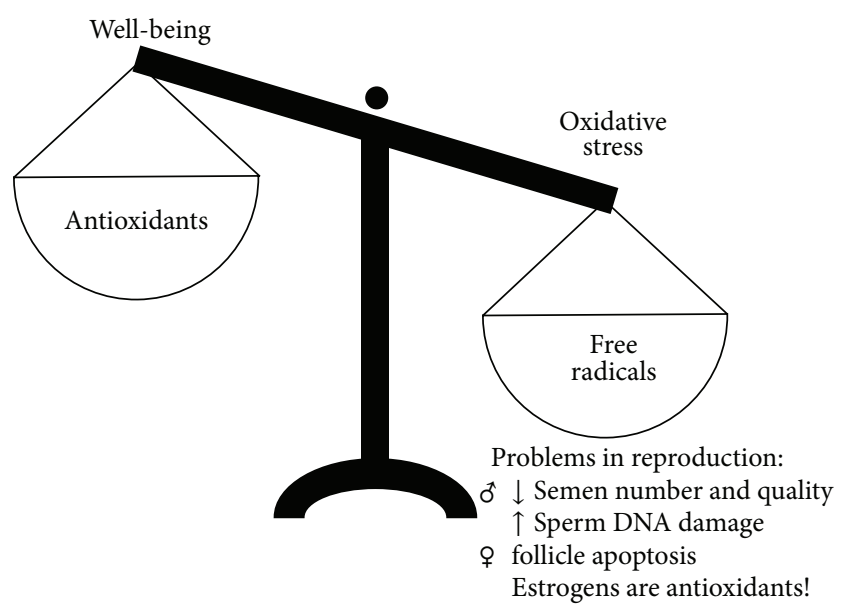

FIGURE 3: Stress at cellular level: an unbalance between production of free radicals (e.g., reactive oxygen species (ROS)) and antioxidant defenses inducing oxidative stress in the cells. Although oxidative stress is widely accepted as an important pathogenic mechanism in different diseases, yet ROS are physiological mediators of transcription control and in many cells (e.g., leukocytes) ROS are protection factors against infectious stimuli. The complete elimination of free radicals would thus disrupt, rather than extend, the normal functioning of the body.

of GCs survival occurs at the expense of reproduction. Therefore we can conclude that the division of resources in the trade-off between survival and reproduction is likely mediated, in part, through regulation of the stress response by the HPA axis [15].

At Cellular Level. Beyond the general beliefs stress can be defined also at cellular level as an oxidative stimulus. Oxidative stress (OS) is an unbalance between production of free radicals, molecules characterized by high reactivity (like reactive oxygen species (ROS) such as superoxide anion, hydrogen peroxide, and the hydroxyl radical) and antioxidant (such as glutathione, vitamins, catalase, superoxide dismutase, and various peroxidases) defenses in biological systems (Figure 3) [16]. Enhancement in ROS and their metabolites can attack the cell membrane, and they can result in modification of the DNA, lipids, and proteins (such as tyrosine nitration and S-glutathionylation), altering enzymatic systems. The imbalance of ROS can eventually lead to epigenetic differences, changes in cellular pathways and transcription factors, produce irreparable alterations, and cause cell death [4]. OS is widely accepted as an important pathogenic mechanism in different diseases like rheumatoid arthritis, myocardial infarction, diabetes mellitus, and so forth [17]. According to the free radical theory (also known as the OS theory) of aging the progressive decline in physiological functions with age is also a result of the accumulation of ROS-induced damage [18]. Among others OS has been identified as one of the many mediators of infertility [19].

On the other hand, in leukocytes and many other cells (endothelial cells, mesangial cells, fibroblasts, thyrocytes, oocytes, Leydig cells, adipocytes, etc.) ROS generation has been assessed to have a positive physiological role protecting the cells from pathological stimuli [16].

\section{Janus Face of Stress}

2.1. Negative Effects. Individuals have limited resources that they can either devote to reproduction or devote to somatic maintenance (e.g., protection against ROS) [20]. Therefore it is not surprising that the general view is that stress, which requires efforts to maintain homeostasis, negatively influences reproduction.

2.1.1. Fertility. Stress-induced trade-offs to reproductive output are evident across species. Animals (mammals, birds, and reptiles), but even plants, all respond to physical stress by decreasing male and female reproductive function [15, 21]. From economical point of view, summer heat stress is a main factor related to low fertility in high-producing dairy herds living in warm areas worldwide [22]. Costs of reproductive effort are also evident: adult female rodents and primates have higher GC levels during lactation [23], which may lead to the development of stress-related disorders like anxiety and depression [24]. Negative consequences of stress are also present in human and are not only an acute, short lasting effect on fertility or mating abilities; but psychological or physical stress experienced by adolescents can alter the onset of puberty, shifting the clock of fertility [25] (Figure 2).

Considering the mechanism of stress-induced infertility, expression of glucocorticoid receptors (GRs) has been described in multiple cell types of the testis and expression is conserved across species. The male gonads are direct targets of GC action controlling testosterone biosynthesis in Leydig cells [26]. Additionally, exogenous and stress-induced GCs cause Leydig cell death $[27,28]$, thereby providing contributing mechanisms to stress-derived androgen dysfunction in males. The role of GCs in the female reproductive tract is realized in the hypothalamus, where it is well established that the stress-activated HPA axis suppresses hypothalamicpituitary-gonadal (HPG) function through influencing the gonadotropin releasing hormone secretion. In addition to direct HPG axis regulation, GCs may regulate novel mediators of the axis like gonadotropin-inhibitory hormone and kisspeptin. Moreover, GRs have also been demonstrated in the ovary, where GCs directly regulate steroid biosynthesis.

Another possible contribution of stress to fertility is at cellular level. Human-made chemicals (among other air pollutants) as well as unhealthy lifestyle behaviours, mainly obesity, tobacco smoking, alcohol consumption, and medical drug abuse, involve the generation of ROS and cellular oxidative damage. More data are available on male reproduction as both spermatogenesis and Leydig cell steroidogenesis are very vulnerable to OS [17]. The impairments in male infertility have resulted via mechanisms involving the induction of peroxidative damage in the sperm plasma membrane, DNA damage, and apoptosis $[19,29]$ leading to metabolic and functional disorders of male germ cells and may be a primary cause of some types of infertility [30]. Motor vehicle exhaust contains variety of toxic components and contributes 
to a large proportion of the air pollution [31]. Its inhalation can cause harmful effects on male reproductive functions by altering organ weights, reducing the spermatozoa qualities, and inducing OS. On the other hand, suboptimal maternal nutrition (both low-protein diet and maternal obesity) is accompanied by enhanced OS in offspring leading to altered sperm function too $[32,33]$. Not only in rodents, but also in humans, paternal obesity is associated with increased OS in sperm, reduction in semen quality, and decreased fertility. Beside direct oxidative damage the OS-induced decrease in fetal lutein hormone concentration has negative consequences on gonadal development leading to decreased testosterone serum levels and sperm concentration [33].

Although females are not that well studied, yet there is strong evidence that ROS are involved in ovarian toxicity as well $[4,34]$. More specifically, several chemical and physical agents induced ROS production, which initiates apoptosis in antral follicles and also in primordial and primary follicle [35]. We have to add, however, that ovarian steroid might have protective role by upregulating the expression of antioxidants [36]. Indeed, many preclinical reports indicated an enhancement in OS after ovariectomy [37] and in postmenopausal women estradiol therapy might decrease the ROS production [38].

Another side of the coin is that free radicals and ROS are produced in direct proportion to metabolic rate as an inevitable consequence of the molecular functioning of mitochondria and the electron transport chain. (This notion was subsequently encapsulated in the "rate of living" theory [39], the idea that living fast is inevitably linked to dying young.) Higher rates of metabolism that accompany reproduction lead to greater free radical production and hence act as a potential mediator of the trade-off between reproduction and survival [20]. This cost of reproduction was confirmed in many different species. For example, an increase in Drosophila melanogaster female reproduction increased the susceptibility to OS [40].

2.1.2. In Utero Stress. Spontaneous miscarriage is the most common adverse pregnancy outcome in humans and occurs in $15-20 \%$ of all recognized pregnancies [41] (Figure 2). The causes for a spontaneous miscarriage are diverse and comprise genetic, endocrinologic, anatomic, immunologic, or microbiologic aspects. Among others, environmental factors such as psychosocial stress have been identified to account for infertility and unexplained reproductive failure in humans and other mammalian species such as baboons, elks, and rodents. Stress has been shown to challenge pregnancy maintenance by initiating an inflammatory response at the fetomaternal interface.

High perceived stress during pregnancy is a risk factor for preterm labor and poor outcomes in offspring [42]. Moreover, a higher frequency of growth-restricted fetuses is a well-documented side effect of GC treatment during pregnancy [43]. Although some form of stress per se might not be harmful (e.g., work-related occupational stress), the presence of other risk factors may result in a synergistic effect which strengthened the odds of an adverse outcome
[44]. It was also established that, for example, disasters as perinatal stressors themselves are not that influential on child development, but the mental health of the mother (disturbed by the disaster) may strongly influence the later development [45].

The consequences of intrauterine stress extend beyond the immediate perinatal period. Epidemiologic studies suggest that elevations in GC exposure during fetal life may result in fetal programming of cardiovascular, metabolic, and neuroendocrine disorders in adult life. In the placenta, conversion of maternal GCs into their inactive metabolites provides a protective barrier. However, following GC excess, this may be ineffective in protecting the fetus from overexposure. In the rat, maternal exposure to dexamethasone (a synthetic GC) during gestation results not only in reduced birth weight, but also in hypertension of the adult offspring $[46,47]$. A nonhuman primate model of intrauterine dexamethasone treatment revealed a dose-dependent reduction in postnatal growth together with impaired glucose tolerance and hyperinsulinemia in offspring [48]. Similarly, antenatal GCs treatment in human offspring also induced insulin resistance [49]. Furthermore, fetal exposure to synthetic GCs is associated with persistent neurological consequences in humans, including cortical thinning [50]. Excessive endogenous GC levels have similar consequences (reduced birth weight and programming effects, e.g., emotional problems) $[51,52]$. One of the underlying mechanisms could be a change in hippocampal GR expression, an important component of the negative feedback loop of the HPA axis [53].

As late, transgenerational consequences, offspring of female rats subjected to restraint or environment stress (e.g., nutrient restriction) during pregnancy experienced fewer and longer pregnancies, with less viable young, as adults [54-56]. Male rats from stressed or GC treated dams also demonstrated reduced sexual behavior and fertility $[57,58]$. An indirect connection between in utero stress and reproduction was that stress, ACTH, or GC treatment of the mice mother during pregnancy induced a subsequent delay in the onset of puberty [59]. Persistent changes in gene expression that remain after the inciting event are thought to be mediated by epigenetic mechanisms [60]. Intrauterine growth restriction in the rat caused changes in epigenetic profile of GR in the hippocampus [61]. Moreover, fetal GC exposure caused significant variations in genome-wide promoter methylation, ultimately leading to profound changes to the epigenetic landscape.

Additionally, not only perinatal stress of the pups [14] but also maternal stress during lactation may alter the development of the offspring [62].

\subsection{Positive Effects}

2.2.1. Fertility. GCs mediate the release of sex steroids thereby regulating the timing of puberty onset. However, an optimum level is needed, as both in the case of hypocortisolism (Addison's disease) and in the case of hypercorticism (Cushing's syndrome) the onset of puberty is altered. 
It is known that preconceptional effects can profoundly alter later pregnancy and the fetus [9]. Despite this fact, in humans, the pregnancy rate is not influenced by injection drug (such as heroin) use [63], known to stimulate the HPA axis [64]. We must mention, however, that low uptake of reliable contraception can confound these results. Nevertheless, appropriate usage of morphine can be even beneficial in enhancing the pregnancy rate, based on a study using embryo transfer in rats [65].

Moreover, physical exercise, which stimulates the HPA axis as well [66], may prevent reproductive complications associated with maternal obesity. The reduction in obesity lowers the risk of infertility and miscarriage, and it may also reduce the probability of obesity-related complications during later pregnancy [67].

A possible mechanism of the enhanced pregnancy rate can be the apoptosis inhibiting effect of GCs on luteal cells, as the maintained luteal function contributes to the survival of the fetus [68].

As a further positive effect at homeostatic levels GCs regulate many key aspects of early pregnancy, including the effects of the maternal immune system, embryo attachment, and invasion, along with the growth and development of the fetus $[15,69]$. Despite the previously mentioned negative consequences, the pregnancy-promoting potential of GCs was also confirmed [70]. It is well established that uterine receptivity and embryo implantation are determined by uterine natural killer (NK) and other cells regulated by the immune system [71]. Daily GC administration suppressed the levels of uterine NK cells in a patient with a history of recurrent miscarriages [72]. These immune modulatory effects of GCs provide a link between stress and reproductive function through improvement of the intrauterine environment. Although some further human cases also suggest positive pregnancy rates and outcomes after preconceptional GC treatment $[73,74]$, yet the association is not that unequivocal [75]. Nevertheless, there are GRs in the uterus and GCs regulate estrogen effect through an interaction with estrogen receptors. Moreover, in relation with reproduction GCs primarily induce an antiapoptotic effect in cells of the mammary gland [15].

With respect to the cellular level, some carefully controlled laboratory work has repeatedly concluded that OS is unchanged or is lower in those individuals that reproduce compared to those that do not despite the reproductionsurvival trade-off (see earlier) [76]. Females have extremely high energetic demands during reproduction, particularly through lactation. However, there was no evidence of increased OS in mice. Instead, in the liver, markers of oxidative damage (malondialdehyde, protein thiols, and the proportion of glutathione in the oxidized form) indicated lower OS in reproducing females when compared with nonreproductive controls. Even during peak lactation, none of the markers of oxidative damage indicated higher OS than among nonreproductive females. Another example is the breeding canaries, which showed decrease in plasma oxidative damage (reactive oxygen metabolites and protein carbonyls) compared both with nonbreeding canaries and premanipulation values irrespective of sex and brood size [77].

The reason might be that, for several transcription factors, ROS are physiological mediators of transcription control. The well-known examples of redox-sensitive transcription factors are nuclear factor- $\kappa \mathrm{B}$ (NF- $\kappa \mathrm{B})$ and activator protein-1 (AP-1). Studies have also demonstrated that low and controlled concentrations of ROS play an important role in normal sperm physiological processes such as capacitation, hyperactivation, acrosome reactions, and signaling processes to ensure appropriate fertilization [19]. The complete elimination of free radicals would thus disrupt, rather than extend, the normal functioning of the body.

Another explanation is that reproduction activates behavioural or physiological mechanisms that protect against OS in order to improve immediate reproductive success and, possibly, not to compromise future reproduction. This may be especially important in species with multiple reproductive cycles over the course of a lifetime.

Moreover, oxidative damage is not necessarily an evolutionary mistake but may be beneficial for evolution [78].

2.2.2. In Utero. GCs are essential in mammals toprepare for life after birth. Their blood levels rise dramatically shortly before birth. GCs trigger parturition not only in animals, but also in humans [79]. However, for labour simultaneously high estrogen levels are also required, but GCs may inhibit the synthesis of the precursors both in fetus and mothers, thereby reducing the placental estrogen synthesis. Thus, the exogenously given GC may not be beneficial; however, the estrogen inhibiting effect of endogenous GC might be counteracted by its degradative enzymes (11-beta-hydroxysteroid dehydrogenase) in the placenta.

If there is any sign of preterm birth, it has become common practice to treat either antenatally the mother or postnatally the infant with GCs to accelerate tissue development, particularly of the lung [80]. This is a rather beneficial effect; however, in the long run it can increase the risk of adverse outcome in later life or even shorter lifespan (see earlier). The perinatal action of the GCs depends on the context and the timing as well as the type of administered steroid. The optimal amount of GCs is very important as either insufficient or excessive GC exposure before birth may alter the normal GC-regulated trajectory of maturation with potential life-long consequences [81].

Controversially, enriched environmental model, where the animals show all endocrine signs of a chronic stress state [82], was beneficial in many preclinical disease models [83, 84]. However, prenatal enriched environment (through the entire pregnancy) per se induced anxiety and depressive-like behaviors with poor attentional performance in male adult offspring [85]. On the other hand it prevented the harmful effect of adult acute stress. Moreover, juvenile enrichment could transgenerationally rescue a genetic defect in long-term potentiation and memory in a knockout mouse strain [86]. Thus, prenatal enriched environment may be also beneficial leading to resilience to adulthood. 
Another model leading to chronic stress is the voluntary wheel running $[66,87]$. The beneficial effect of physical activity in many disease states is well-documented. In rodents, wheel running during pregnancy transiently enhanced memory and hippocampal neurogenesis in the offspring until preadolescence $[88,89]$. Exercise during pregnancy provided long lasting protection from neurodegeneration and improved brain plasticity in the otherwise unstimulated progeny [90]. Moreover, maternal voluntary wheel running significantly offset morphological impairments due to prenatal stress (maternal restraint) in the offspring [91]. In humans, maternal exercise during pregnancy positively influenced fetal health and offspring's cognitive performance until childhood [92]. Women who are the most physically active had the lowest prevalence of gestational diabetes with decreased incidence of obesity and type 2 diabetes in both mother and offspring [67]. Exercise during pregnancy and lactation prevented maternal obesity-induced elevation in corticosterone in rat offspring as well [93]. Thus, in addition to maintaining physical fitness in the pregnant women, exercise may be beneficial in preventing or treating maternal-fetal diseases.

Although in utero stress mostly results in low birth weight, yet some authors reported even increased birth weight after intrauterine protein restriction [94]. We have to add, however, that even in this case the pups had proportionally smaller brains and at weaning rats exposed to low-protein diets in utero had significantly higher systolic blood pressure relative to control animals.

The long-term consequences of in utero stimuli might be dependent on the later environment. For example, the offspring of protein restricted mothers lived longer than absolute controls if they were to grow up on protein restricted diet; however, a normal diet shortened their life [56]. This effect might be induced by predictive adaptive response (a kind of preconditioning) [10]. It means that the organism adapts to a certain environment in utero and in case after birth the eventually experienced environment matches the predicted environment, the organism's phenotype proves to be adapted and life span is extended.

Positive effect of stress was detected also in the case when repeated maternal stress was applied during the lactation period [95]. Male offspring of these mothers favoured goal-directed behaviours and showed enhanced behavioural flexibility in their adulthood. Additionally, when the mothers' drinking water was supplemented with a low dose corticosterone $(0.2 \mathrm{mg} / \mathrm{mL}$ ) during the lactation (reflecting a form of mild environmental stimulation), the offspring develop the ability to cope better with different situations during life [13]. The progeny of these mothers, once adults, showed improved learning capabilities, reduced fearfulness in anxiogenic situations and resistance to ischemic neuronal damage, and adapted better to colonic inflammatory stress. This protective effect is linked to hyporeactive HPA axis due to epigenetically transmitted enhanced negative feedback in the hippocampus.

\section{Intervention Options}

Taking into consideration thegrowing infertility public health issue worldwide it is important to prevent the negative consequences of stress on reproduction.

3.1. Body Stress. Because stress is considered to be number one killer, several methods (many belonging to alternative medicine) have been developed for stress relief. It is clear that the mental status of the parents can profoundly alter the fertility $[96,97]$ and stress has a great impact on the psyche [24]. Therefore mental well-being is an important factor [98], which can be reached by different relaxations techniques (mental or physical), nutritional interventions, and pharmacological treatments. Psychological interventions were found to improve some patients' chances of becoming pregnant [99] and relaxation may prevent preterm labour [100]. Massage therapy may be also relaxing [101]. Physical activity is a good example of eustress [67]. The beneficial effect of exercise [102] may be due-at least partly-to its trophic effect through, for example, an enhanced brain derived growth factor level in the hippocampus [103]. Pharmacological intervention is focused mainly on the treatment of stress-related disorders, thereby preventing secondary diseases. For example, pain killers [104], anxiolytics [105], and antidepressant are all good for stress relief, thereby enhancing the spirit for reproduction, but their potential for enhancing, for example, the pregnancy rate is not known, yet.

3.2. Oxidative Stress. Already plants have evolved a plethora of mechanisms to circumvent the potential damaging effects of OS. These mechanisms include different levels of organization, from root-shoot signalling at the whole-plant level to specific biochemical responses at the subcellular level, such as reductions in photosynthesis and the consequent activation of photo- and antioxidant mechanisms in chloroplasts [106].

In mammals different antioxidant systems help to protect the body against OS. For example, the MRE11 complex is an important source of stress relief, being a key component of DNA repair [107]. The most studied antioxidants are ascorbic acid (Vitamin C), tocopherols (Vitamin E), and carotenoids (Vitamin A), but enzymes, as well as Vitamin B complex, glutathione, pantothenic acid, coenzyme Q10, and carnitine, and micronutrients such as zinc, selenium, and copper seem to be also important $[29,108,109]$. However, only low quality evidence suggests that antioxidant supplementation in subfertile males may improve clinical pregnancy rates [5] and in pregnant women there were no changes in smoking induced OS in relation to vitamin supplement intake [110].

Because of high incidence obesity is one of the most prevalent sources of OS [32]. Weight loss inducing lifestyle changes such as dietary and exercise interventions has beneficial effects on metabolism both in rodents and in humans [102]. In obese men weight loss can improve semen parameters and therefore fertility. 


\section{Conclusion}

As many other processes, stress has also two faces; it is at the same time the good and the bad guy. We have to be aware that the most important thing is the balance, not too much, but also not too little (Figure 1).

A stress situation in itself does not affect health harmfully when it is accompanied by the feeling that one is able to overcome difficulties successfully, which is actually the basis of physical and mental development [11]. Challenges and new situations lead to deterioration if one does not know the solutions, if one is faced with too long lasting, too many, and seemingly unsolvable situations, and if society seems unpredictable, chaotic, and uncontrollable. The distress is the hotbed of reproductive disabilities as well. However, eustress, a certain level of HPA axis activation, is important for normal fertility and pregnancy as well as intrauterine and later development. An optimal level of stress is required for resilience to bigger, harmful challenges.

At cellular level, when the natural balance between ROS and antioxidants is disturbed, the first restorative measure to be taken should be changes in lifestyle, such as cessation of smoking, limiting substance use, and maintaining a healthy and balanced diet, which all may increase the reproductional capacity. Antioxidant supplementation may be taken to improve the patient's health outcomes including fertility, pregnancy rate, and normal pregnancy [19]. We have to be aware that males are more vulnerable to OS than females because of the protective role of estrogens. On the other hand, it appears that threshold levels for the benefit or harm of OS exist. Therefore care must be given to acknowledge potential undesirable effects of excessive vitamin supplementation [111].

\section{Abbreviations}

ACTH: Adrenocorticotropin

AP-1: Activator protein-1

AVP: vasopressin

CRH: Corticotropin-releasing hormone

GC: Glucocorticoid

GR: Glucocorticoid receptors

HPA: Hypothalamic-pituitary-adrenocortical axis

HPG: Hypothalamic-pituitary-gonadal

NF- $\kappa$ B: Nuclear factor $-\kappa B$

NK: Natural killer

OS: Oxidative stress

PVN: Nucleus paraventricularis hypothalamic

ROS: Reactive oxygen species.

\section{Conflict of Interests}

The author declares that there is no conflict of interests regarding the publication of this paper.

\section{References}

[1] J. Boivin, L. Bunting, J. A. Collins, and K. G. Nygren, "International estimates of infertility prevalence and treatment-seeking: potential need and demand for infertility medical care," Human Reproduction, vol. 22, no. 6, pp. 1506-1512, 2007.

[2] S. J. Dyer, "International estimates on infertility prevalence and treatment seeking: potential need and demand for medical care," Human Reproduction, vol. 24, no. 9, pp. 2379-2380, 2009.

[3] WHO, 2004, http://www.who.int/reproductivehealth/topics/infertility/burden/en/.

[4] S. Gupta, J. Ghulmiyyah, R. Sharma, J. Halabi, and A. Agarwal, "Power of proteomics in linking oxidative stress and female infertility," BioMed Research International, vol. 2014, Article ID 916212, 26 pages, 2014.

[5] M. G. Showell, R. Mackenzie-Proctor, J. Brown, A. Yazdani, M. T. Stankiewicz, and R. J. Hart, "Antioxidants for male subfertility," Cochrane Database of Systematic Reviews, no. 12, Article ID CD007411, 2014.

[6] Wikipedia, http://en.wikipedia.org/wiki/Reproduction.

[7] Biotopics, http://www.biotopics.co.uk/genes1/asexual_and_sexual_reproduction.html.

[8] World-Builders, http://www.world-builders.org/lessons/less/biomes/breeding.html.

[9] A. Fodor, J. Tímár, and D. Zelena, "Behavioral effects of perinatal opioid exposure," Life Sciences, vol. 104, no. 1-2, pp. 1-8, 2014.

[10] P. D. Gluckman and M. A. Hanson, "Living with the past: evolution, development, and patterns of disease," Science, vol. 305, no. 5691, pp. 1733-1736, 2004.

[11] M. Kopp, "Public health burden of chronic stress in a transforming society," Psychological Topics, vol. 16, no. 2, pp. 297-310, 2007.

[12] H. Selye, Stress without Distress, Lippincott, 1974.

[13] C. Petrella, C. Giuli, S. Agostini et al., "Maternal exposure to low levels of corticosterone during lactation protects against experimental inflammatory colitis-induced damage in adult rat offspring," PLoS ONE, vol. 9, no. 11, Article ID el13389, 2014.

[14] D. Zelena, B. Stocker, I. Barna, Z. E. Tóth, and G. B. Makara, "Vasopressin deficiency diminishes acute and long-term consequences of maternal deprivation in male rat pups," Psychoneuroendocrinology, vol. 51, pp. 378-391, 2015.

[15] S. Whirledge and J. A. Cidlowski, "A role for glucocorticoids in stress-impaired reproduction: beyond the hypothalamus and pituitary," Endocrinology, vol. 154, no. 12, pp. 4450-4468, 2013.

[16] A. Mancini, S. Raimondo, M. Persano et al., "Estrogens as antioxidant modulators in human fertility," International Journal of Endocrinology, vol. 2013, Article ID 607939, 6 pages, 2013.

[17] T. Morielli and C. O'Flaherty, “Oxidative stress impairs function and increases redox protein modifications in human spermatozoa," Reproduction, vol. 149, no. 1, pp. 113-123, 2014.

[18] D. G. Ivanova and T. M. Yankova, "The free radical theory of aging in search of a strategy for increasing life span," Folia Medica (Plovdiv), vol. 55, no. 1, pp. 33-41, 2013.

[19] A. Agarwal, G. Virk, C. Ong, and S. S. du Plessis, "Effect of oxidative stress on male reproduction," The World Journal of Men's Health, vol. 32, no. 1, pp. 1-17, 2014.

[20] J. R. Speakman and M. Garratt, "Oxidative stress as a cost of reproduction: beyond the simplistic trade-off model," BioEssays, vol. 36, no. 1, pp. 93-106, 2014.

[21] N. de Storme and D. Geelen, "The impact of environmental stress on male reproductive development in plants: biological 
processes and molecular mechanisms," Plant, Cell and Environment, vol. 37, no. 1, pp. 1-18, 2014.

[22] F. López-Gatius, "Factors of a noninfectious nature affecting fertility after artificial insemination in lactating dairy cows. A review," Theriogenology, vol. 77, no. 6, pp. 1029-1041, 2012.

[23] D. Maestripieri and A. V. Georgiev, "What cortisol can tell us about the costs of sociality and reproduction among freeranging rhesus macaque females on Cayo Santiago," The American Journal of Primatology, 2015.

[24] D. Zelena, "Vasopressin in health and disease with a focus on affective disorders," Central Nervous System Agents in Medicinal Chemistry, vol. 12, no. 4, pp. 286-303, 2012.

[25] J. A. Magner, A. D. Rogol, and P. Gorden, "Reversible growth hormone deficiency and delayed puberty triggered by a stressful experience in a young adult," American Journal of Medicine, vol. 76, no. 4, pp. 737-742, 1984.

[26] D. Evain, A. M. Morera, and J. M. Saez, "Glucocorticoids receptors in rat testis: their role in Leydig cells specific function and DNA synthesis," Annales d'Endocrinologie, vol. 37, no. 2, pp. 101-102, 1976.

[27] H. B. Gao, M. H. Tong, Y. Q. Hu, Q. S. Guo, R. Ge, and M. P. Hardy, "Glucocorticoid induces apoptosis in rat Leydig cells," Endocrinology, vol. 143, no. 1, pp. 130-138, 2002.

[28] Y. Chen, Q. Wang, F.-F. Wang, H.-B. Gao, and P. Zhang, "Stress induces glucocorticoid-mediated apoptosis of rat Leydig cells in vivo," Stress, vol. 15, no. 1, pp. 74-84, 2012.

[29] R. Walczak-Jedrzejowska, J. K. Wolski, and J. SlowikowskaHilczer, "The role of oxidative stress and antioxidants in male fertility," Central European Journal of Urology, vol. 66, no. 1, pp. 60-67, 2013.

[30] S. Kumar, S. Murarka, V. V. Mishra, and A. K. Gautam, "Environmental \& lifestyle factors in deterioration of male reproductive health," The Indian Journal of Medical Research, vol. 140, no. 7, supplement, pp. S29-S35, 2014.

[31] D. Rengaraj, W. S. Kwon, and M. G. Pang, "Effects of motor vehicle exhaust on male reproductive function and associated proteins," Journal of Proteome Research, vol. 14, no. 1, pp. 22-37, 2015.

[32] M. Santos, G. L. Rodríguez-González, C. Ibáñez, C. C. Vega, P. W. Nathanielsz, and E. Zambrano, "Adult exercise effects on oxidative stress and reproductive programming in male offspring of obese rats," The American Journal of PhysiologyRegulatory, Integrative and Comparative Physiology, vol. 308, no. 3, pp. R219-R225, 2015.

[33] G. L. Rodríguez-González, L. A. Reyes-Castro, C. C. Vega et al., "Accelerated aging of reproductive capacity in male rat offspring of protein-restricted mothers is associated with increased testicular and sperm oxidative stress," AGE, vol. 36, no. 6, article 9721, 2014.

[34] A. Agarwal, A. Aponte-Mellado, B. J. Premkumar, A. Shaman, and S. Gupta, "The effects of oxidative stress on female reproduction: a review," Reproductive Biology and Endocrinology, vol. 10, article 49, 2012.

[35] U. Luderer, "Ovarian toxicity from reactive oxygen species," Vitamins and Hormones, vol. 94, pp. 99-127, 2014.

[36] J. Viña, J. Gambini, F. J. García-García, L. Rodriguez-Mañas, and C. Borrás, "Role of oestrogens on oxidative stress and inflammation in ageing," Hormone Molecular Biology and Clinical Investigation, vol. 16, no. 2, pp. 65-72, 2013.

[37] M. Szczubial, M. Kankofer, M. Bochniarz, and R. Dąbrowski, "Effects of ovariohysterectomy on oxidative stress markers in female dogs," Reproduction in Domestic Animals, 2015.
[38] Y. Zhang, Y. He, Y. Zong et al., "17 $\beta$-estradiol attenuates homocysteine-induced oxidative stress and inflammatory response as well as MAPKs cascade via activating PI3-K/Akt signal transduction pathway in Raw 264.7 cells," Acta Biochimica et Biophysica Sinica, vol. 47, no. 2, pp. 65-72, 2015.

[39] R. Pearl, The Rate of Living, University of London Press, London, UK, 1928.

[40] A. B. Salmon, D. B. Marx, and L. G. Harshman, "A cost of reproduction in Drosophila melanogaster: stress susceptibility," Evolution, vol. 55, no. 8, pp. 1600-1608, 2001.

[41] A. Friebe and P. Arck, "Causes for spontaneous abortion: what the bugs 'gut' to do with it?" International Journal of Biochemistry and Cell Biology, vol. 40, no. 11, pp. 2348-2352, 2008.

[42] R. A. Mancuso, C. D. Schetter, C. M. Rini, S. C. Roesch, and C. J. Hobel, "Maternal prenatal anxiety and corticotropin-releasing hormone associated with timing of delivery," Psychosomatic Medicine, vol. 66, no. 5, pp. 762-769, 2004.

[43] J. M. Reinisch, N. G. Simon, W. G. Karow, and R. Gandelman, "Prenatal exposure to prednisone in humans and animals retards intrauterine growth," Science, vol. 202, no. 4366, pp. 436438, 1978.

[44] M. Mutambudzi, J. D. Meyer, N. Warren, and S. Reisine, "Effects of psychosocial characteristics of work on pregnancy outcomes: a critical review," Women \& Health, vol. 51, no. 3, pp. 279-297, 2011.

[45] E. Harville, X. Xiong, and P. Buekens, "Disasters and perinatal health: a systematic review," Obstetrical and Gynecological Survey, vol. 65, no. 11, pp. 713-728, 2010.

[46] N. S. Levitt, R. S. Lindsay, M. C. Holmes, and J. R. Seckl, “Dexamethasone in the last week of pregnancy attenuates hippocampal glucocorticoid receptor gene expression and elevates blood pressure in the adult offspring in the rat," Neuroendocrinology, vol. 64, no. 6, pp. 412-418, 1996.

[47] L. A. Ortiz, A. Quan, F. Zarzar, A. Weinberg, and M. Baum, "Prenatal dexamethasone programs hypertension and renal injury in the rat," Hypertension, vol. 41, no. 2, pp. 328-334, 2003.

[48] A. de Vries, M. C. Holmes, A. Heijnis et al., "Prenatal dexamethasone exposure induces changes in nonhuman primate offspring cardiometabolic and hypothalamic-pituitary-adrenal axis function," The Journal of Clinical Investigation, vol. 117, no. 4, pp. 1058-1067, 2007.

[49] S. R. Dalziel, N. K. Walker, V. Parag et al., "Cardiovascular risk factors after antenatal exposure to betamethasone: 30-year follow-up of a randomised controlled trial," The Lancet, vol. 365, no. 9474, pp. 1856-1862, 2005.

[50] E. P. Davis, C. A. Sandman, C. Buss, D. A. Wing, and K. Head, "Fetal glucocorticoid exposure is associated with preadolescent brain development," Biological Psychiatry, vol. 74, no. 9, pp. 647655, 2013.

[51] F. Rice, I. Jones, and A. Thapar, “The impact of gestational stress and prenatal growth on emotional problems in offspring: a review," Acta Psychiatrica Scandinavica, vol. 115, no. 3, pp. 171$183,2007$.

[52] M. C. Holmes, C. T. Abrahamsen, K. L. French, J. M. Paterson, J. J. Mullins, and J. R. Seckl, "The mother or the fetus? $11 \beta$ hydroxysteroid dehydrogenase type 2 null mice provide evidence for direct fetal programming of behavior by endogenous glucocorticoids," Journal of Neuroscience, vol. 26, no. 14, pp. 3840-3844, 2006. 
[53] E. R. de Kloet, E. Vreugdenhil, M. S. Oitzl, and M. Joëls, "Brain corticosteroid receptor balance in health and disease," Endocrine Reviews, vol. 19, no. 3, pp. 269-301, 1998.

[54] L. R. Herrenkohl, "Prenatal stress reduces fertility and fecundity in female offspring," Science, vol. 206, no. 4422, pp. 1097-1099, 1979.

[55] E. W. Carney, J. W. Crissman, A. B. Liberacki, C. M. Clements, and W. J. Breslin, "Assessment of adult and neonatal reproductive parameters in Sprague-Dawley rats exposed to propylene glycol monomethyl ether vapors for two generations," Toxicological Sciences, vol. 50, no. 2, pp. 249-258, 1999.

[56] C. Guzmán, R. Cabrera, M. Cárdenas, F. Larrea, P. W. Nathanielsz, and E. Zambrano, "Protein restriction during fetal and neonatal development in the rat alters reproductive function and accelerates reproductive ageing in female progeny," The Journal of Physiology, vol. 572, part 1, pp. 97-108, 2006.

[57] C. J. Crump and P. F. D. Chevins, "Prenatal stress reduces fertility of male offspring in mice, without affecting their adult testosterone levels," Hormones and Behavior, vol. 23, no. 3, pp. 333-343, 1989.

[58] F. Stylianopoulou, M. Fameli, E. Brountzos, and A. N. Contopoulos, "Neonatal neural organizing effects of exogenous corticosteroids on sexual differentiation of the brain in the female rat," Hormones and Behavior, vol. 17, no. 3, pp. 332-341, 1983.

[59] J. T. Smith and B. J. Waddell, "Increased fetal glucocorticoid exposure delays puberty onset in postnatal life," Endocrinology, vol. 141, no. 7, pp. 2422-2428, 2000.

[60] D. Zelena, "Co-regulation and epigenetic dysregulation in schizophrenia and bipolar disorder," in Patho-Epigenetics of Disease, J. Minarovits and H. H. Niller, Eds., pp. 281-348, Springer Science+Business Media B.V., New York, NY, USA, 2012.

[61] X. Ke, M. E. Schober, R. A. McKnight et al., "Intrauterine growth retardation affects expression and epigenetic characteristics of the rat hippocampal glucocorticoid receptor gene," Physiological Genomics, vol. 42, no. 2, pp. 177-189, 2010.

[62] A. Fodor and D. Zelena, "The effect of maternal stress activation on the offspring during lactation in light of vasopressin," The Scientific World Journal, vol. 2014, Article ID 265394, 15 pages, 2014.

[63] A. E. Weber, M. W. Tyndall, P. M. Spittal et al., "High pregnancy rates and reproductive health indicators among female injection-drug users in Vancouver, Canada," European Journal of Contraception and Reproductive Health Care, vol. 8, no. 1, pp. 52-58, 2003.

[64] D. Jezova, M. Mlynarik, D. Zelena, and G. B. Makara, "Behavioral sensitization to intermittent morphine in mice is accompanied by reduced adrenocorticotropine but not corticosterone responses," Brain Research, vol. 1021, no. 1, pp. 63-68, 2004.

[65] J. C. Smith, T. J. Corbin, J. G. McCabe, and B. Bolon, "Isoflurane with morphine is a suitable anaesthetic regimen for embryo transfer in the production of transgenic rats," Laboratory Animals, vol. 38, no. 1, pp. 38-43, 2004.

[66] A. M. Stranahan, K. Lee, and M. P. Mattson, "Central mechanisms of HPA axis regulation by voluntary exercise," NeuroMolecular Medicine, vol. 10, no. 2, pp. 118-127, 2008.

[67] T. L. Weissgerber, L. A. Wolfe, G. A. L. Davies, and M. F. Mottola, "Exercise in the prevention and treatment of maternal-fetal disease: a review of the literature," Applied Physiology, Nutrition and Metabolism, vol. 31, no. 6, pp. 661-674, 2006.
[68] S. Kawaguchi, A. Bowolaksono, R. Sakumoto, and K. Okuda, "Luteoprotective roles of luteinizing hormone are mediated by not only progesterone production but also glucocorticoid conversion in bovine corpus luteum," Molecular Reproduction and Development, vol. 80, no. 3, pp. 204-211, 2013.

[69] A. E. Michael and A. T. Papageorghiou, "Potential significance of physiological and pharmacological glucocorticoids in early pregnancy," Human Reproduction Update, vol. 14, no. 5, pp. 497$517,2008$.

[70] H. T. Duong, K. K. Piotrowska-Tomala, T. J. Acosta et al., "Effects of cortisol on pregnancy rate and corpus luteum function in heifers: an in vivo study," Journal of Reproduction and Development, vol. 58, no. 2, pp. 223-230, 2012.

[71] S. A. Robertson, "Immune regulation of conception and embryo implantation-all about quality control?" Journal of Reproductive Immunology, vol. 85, no. 1, pp. 51-57, 2010.

[72] S. Quenby, C. Kalumbi, M. Bates, R. Farquharson, and G. Vince, "Prednisolone reduces preconceptual endometrial natural killer cells in women with recurrent miscarriage," Fertility and Sterility, vol. 84, no. 4, pp. 980-984, 2005.

[73] S. Quenby, R. Farquharson, M. Young, and G. Vince, "Successful pregnancy outcome following 19 consecutive miscarriages: case report," Human Reproduction, vol. 18, no. 12, pp. 2562-2564, 2003.

[74] M. Ogasawara and K. Aoki, "Successful uterine steroid therapy in a case with a history of ten miscarriages," American Journal of Reproductive Immunology, vol. 44, no. 4, pp. 253-255, 2000.

[75] C. M. Boomsma, S. D. Keay, and N. S. Macklon, "Periimplantation glucocorticoid administration for assisted reproductive technology cycles," Cochrane Database of Systematic Reviews, no. 1, Article ID CD005996, 2007.

[76] M. Garratt, A. Vasilaki, P. Stockley, F. McArdle, M. Jackson, and J. L. Hurst, "Is oxidative stress a physiological cost of reproduction? An experimental test in house mice," Proceedings of the Royal Society B: Biological Sciences, vol. 278, no. 1708, pp. 1098-1106, 2011.

[77] D. Costantini, G. Casasole, and M. Eens, "Does reproduction protect against oxidative stress?" Journal of Experimental Biology, vol. 217, part 23, pp. 4237-4243, 2014.

[78] B. Poljsak, I. Milisav, T. Lampe, and I. Ostan, "Reproductive benefit of oxidative damage: an oxidative stress 'malevolence?" Oxidative Medicine and Cellular Longevity, vol. 2011, Article ID 760978, 9 pages, 2011.

[79] X. Q. Li, P. Zhu, L. Myatt, and K. Sun, "Roles of glucocorticoids in human parturition: a controversial fact?" Placenta, vol. 35, no. 5, pp. 291-296, 2014.

[80] E. R. de Kloet, S. E. Claessens, and J. Kentrop, "Context modulates outcome of perinatal glucocorticoid action in the brain," Frontiers in Endocrinology, vol. 5, article 100, 2014.

[81] E. A. Rog-Zielinska, R. V. Richardson, M. A. Denvir, and K. E. Chapman, "Glucocorticoids and foetal heart maturation; implications for prematurity and foetal programming," Journal of Molecular Endocrinology, vol. 52, no. 2, pp. R125-R135, 2014.

[82] F. Moncek, R. Duncko, B. B. Johansson, and D. Jezova, "Effect of environmental enrichment on strees related systems in rats," Journal of Neuroendocrinology, vol. 16, no. 5, pp. 423-431, 2004.

[83] K. Takuma, Y. Ago, and T. Matsuda, "Preventive effects of an enriched environment on rodent psychiatric disorder models," Journal of Pharmacological Sciences, vol. 117, no. 2, pp. 71-76, 2011. 
[84] H. Janssen, J. Bernhardt, J. M. Collier et al., "An enriched environment improves sensorimotor function post-ischemic stroke," Neurorehabilitation and Neural Repair, vol. 24, no. 9, pp. 802-813, 2010.

[85] A. Cymerblit-Sabba, T. Lasri, M. Gruper, S. Aga-Mizrachi, S. Zubedat, and A. Avital, "Prenatal Enriched Environment improves emotional and attentional reactivity to adulthood stress," Behavioural Brain Research, vol. 241, no. 1, pp. 185-190, 2013.

[86] J. A. Arai, S. Li, D. M. Hartley, and L. A. Feig, "Transgenerational rescue of a genetic defect in long-term potentiation and memory formation by juvenile enrichment," The Journal of Neuroscience, vol. 29, no. 5, pp. 1496-1502, 2009.

[87] S. K. Droste, A. Gesing, S. Ulbricht, M. B. Müller, A. C. E. Linthorst, and J. M. H. M. Reul, "Effects of long-term voluntary exercise on the mouse hypothalamic-pituitary-adrenocortical axis," Endocrinology, vol. 144, no. 7, pp. 3012-3023, 2003.

[88] H. Kim, S.-H. Lee, S.-S. Kim, J.-H. Yoo, and C.-J. Kim, “The influence of maternal treadmill running during pregnancy on short-term memory and hippocampal cell survival in rat pups," International Journal of Developmental Neuroscience, vol. 25, no. 4, pp. 243-249, 2007.

[89] A. Bick-Sander, B. Steiner, S. A. Wolf, H. Babu, and G. Kempermann, "Running in pregnancy transiently increases postnatal hippocampal neurogenesis in the offspring," Proceedings of the National Academy of Sciences of the United States of America, vol. 103, no. 10, pp. 3852-3857, 2006.

[90] A. Herring, A. Donath, M. Yarmolenko et al., "Exercise during pregnancy mitigates Alzheimer-like pathology in mouse offspring," The FASEB Journal, vol. 26, no. 1, pp. 117-128, 2012.

[91] C. Bustamante, R. Henríquez, F. Medina, C. Reinoso, R. Vargas, and R. Pascual, "Maternal exercise during pregnancy ameliorates the postnatal neuronal impairments induced by prenatal restraint stress in mice," International Journal of Developmental Neuroscience, vol. 31, no. 4, pp. 267-273, 2013.

[92] J. F. Clapp III, "Morphometric and neurodevelopmental outcome at age five years of the offspring of women who continued to exercise regularly throughout pregnancy," Journal of Pediatrics, vol. 129, no. 6, pp. 856-863, 1996.

[93] C. C. Vega, L. A. Reyes-Castro, C. J. Bautista, F. Larrea, P. W. Nathanielsz, and E. Zambrano, "Exercise in obese female rats has beneficial effects on maternal and male and female offspring metabolism," International Journal of Obesity (London), 2013.

[94] S. C. Langley-Evans, D. S. Gardner, and A. A. Jackson, "Association of disproportionate growth of fetal rats in late gestation with raised systolic blood pressure in later life," Journal of Reproduction and Fertility, vol. 106, no. 2, pp. 307-312, 1996.

[95] K. Gapp, S. Soldado-Magraner, M. Alvarez-Sánchez et al., "Early life stress in fathers improves behavioural flexibility in their offspring," Nature Communications, vol. 5, article 5466, 2014.

[96] J. R. W. Fisher and K. Hammarberg, "Psychological and social aspects of infertility in men: an overview of the evidence and implications for psychologically informed clinical care and future resarch," Asian Journal of Andrology, vol. 14, no. 1, pp. 121$129,2012$.

[97] S. Lolak, N. Rashid, and T. N. Wise, "Interface of women's mental and reproductive health," Current Psychiatry Reports, vol. 7, no. 3, pp. 220-227, 2005.

[98] J. A. Sedgeman, "Health Realization/Innate Health: can a quiet mind and a positive feeling state be accessible over the lifespan without stress-relief techniques?" Medical Science Monitor, vol. 11, no. 12, pp. HY47-HY52, 2005.
[99] K. Hämmerli, H. Znoj, and J. Barth, "The efficacy of psychological interventions for infertile patients: a meta-analysis examining mental health and pregnancy rate," Human Reproduction Update, vol. 15, no. 3, pp. 279-295, 2009.

[100] B. Khianman, P. Pattanittum, J. Thinkhamrop, and P. Lumbiganon, "Relaxation therapy for preventing and treating preterm labour," The Cochrane Database of Systematic Reviews, vol. 8, Article ID CD007426, 2012.

[101] T. Field, "Massage therapy research review," Complementary Therapies in Clinical Practice, vol. 20, no. 4, pp. 224-229, 2014.

[102] K. K. V. Haack and I. H. Zucker, "Central mechanisms for exercise training-induced reduction in sympatho-excitation in chronic heart failure," Autonomic Neuroscience: Basic \& Clinical, vol. 188, pp. 44-50, 2015.

[103] P. V. Holmes, "Trophic mechanisms for exercise-induced stress resilience: potential role of interactions between BDNF and galanin," Frontiers in Psychiatry, vol. 5, article 90, 2014.

[104] A. C. Johnson and B. Greenwood-van Meerveld, "Stressinduced pain: a target for the development of novel therapeutics," Journal of Pharmacology and Experimental Therapeutics, vol. 351, no. 2, pp. 327-335, 2014.

[105] E. J. Hoffman and S. J. Mathew, "Anxiety disorders: a comprehensive review of pharmacotherapies," Mount Sinai Journal of Medicine, vol. 75, no. 3, pp. 248-262, 2008.

[106] I. Hernandez and S. Munne-Bosch, "Linking phosphorus availability with photo-oxidative stress in plants," Journal of Experimental Botany, 2015.

[107] K. Rein and T. H. Stracker, "The MRE1l complex: an important source of stress relief," Experimental Cell Research, vol. 329, no. 1, pp. 162-169, 2014.

[108] D. Costantini, "Oxidative stress in ecology and evolution: lessons from avian studies," Ecology Letters, vol. 11, no. 11, pp. 1238-1251, 2008.

[109] J. Wu, S. Wu, Y. Xie et al., "Zinc protects sperm from being damaged by reactive oxygen species in assisted reproduction techniques," Reproductive BioMedicine Online, 2015.

[110] D. Ardalić, A. Stefanović, J. Kotur-Stevuljević et al., "The influence of maternal smoking habits before pregnancy and antioxidative supplementation during pregnancy on oxidative stress status in a non-complicated pregnancy," Advances in Clinical and Experimental Medicine, vol. 23, no. 4, pp. 575-583, 2014.

[111] E. H. Ruder, T. J. Hartman, J. Blumberg, and M. B. Goldman, "Oxidative stress and antioxidants: exposure and impact on female fertility," Human Reproduction Update, vol. 14, no. 4, pp. 345-357, 2008. 




The Scientific World Journal
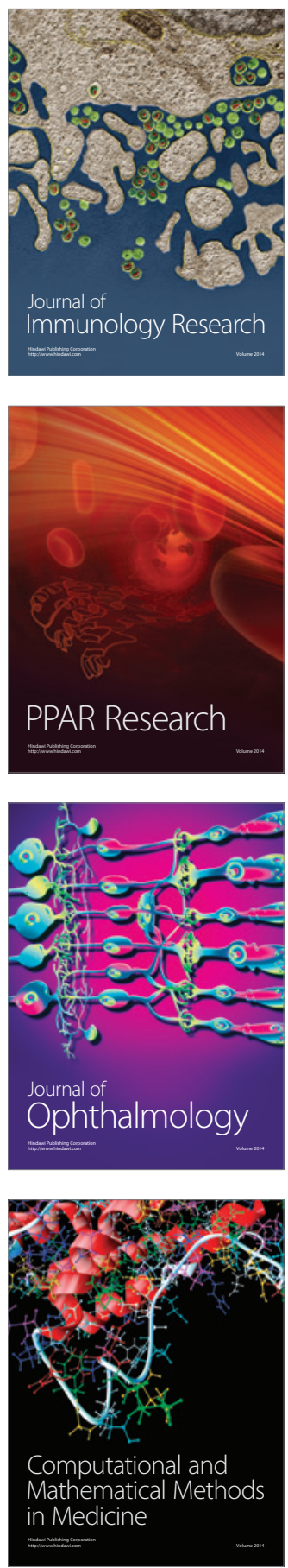

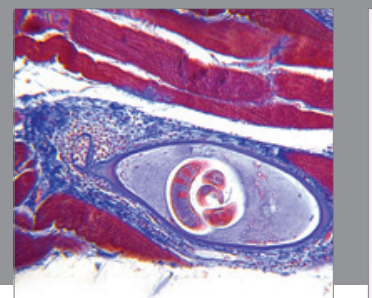

Gastroenterology

Research and Practice
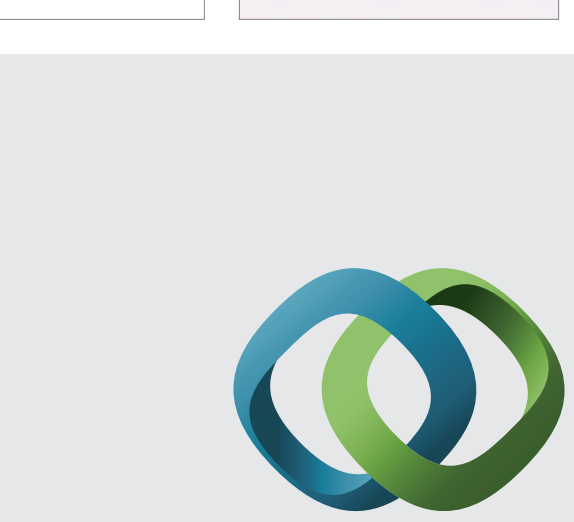

\section{Hindawi}

Submit your manuscripts at

http://www.hindawi.com
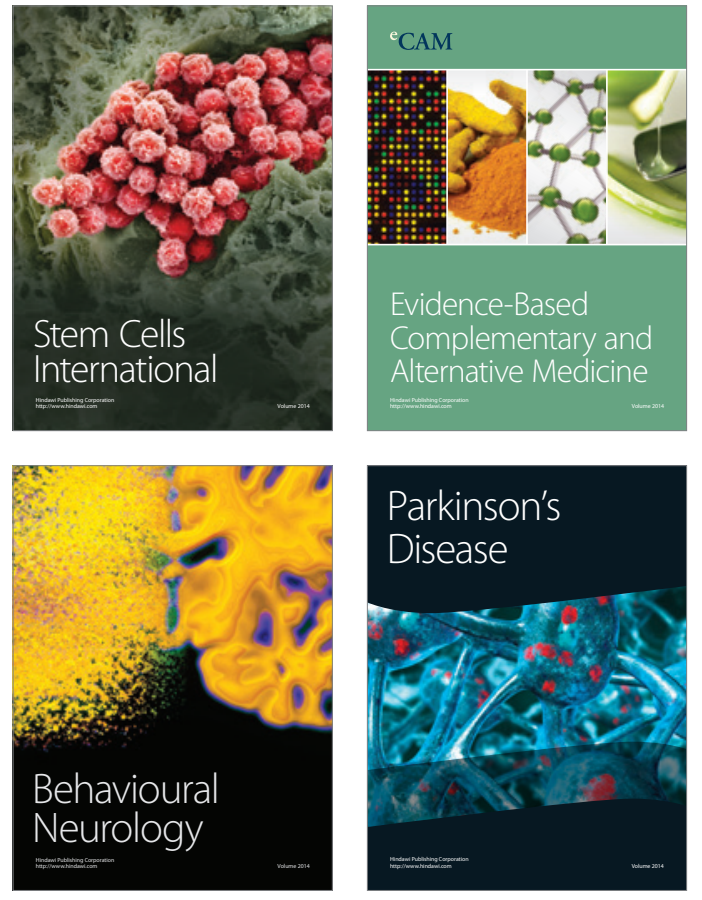
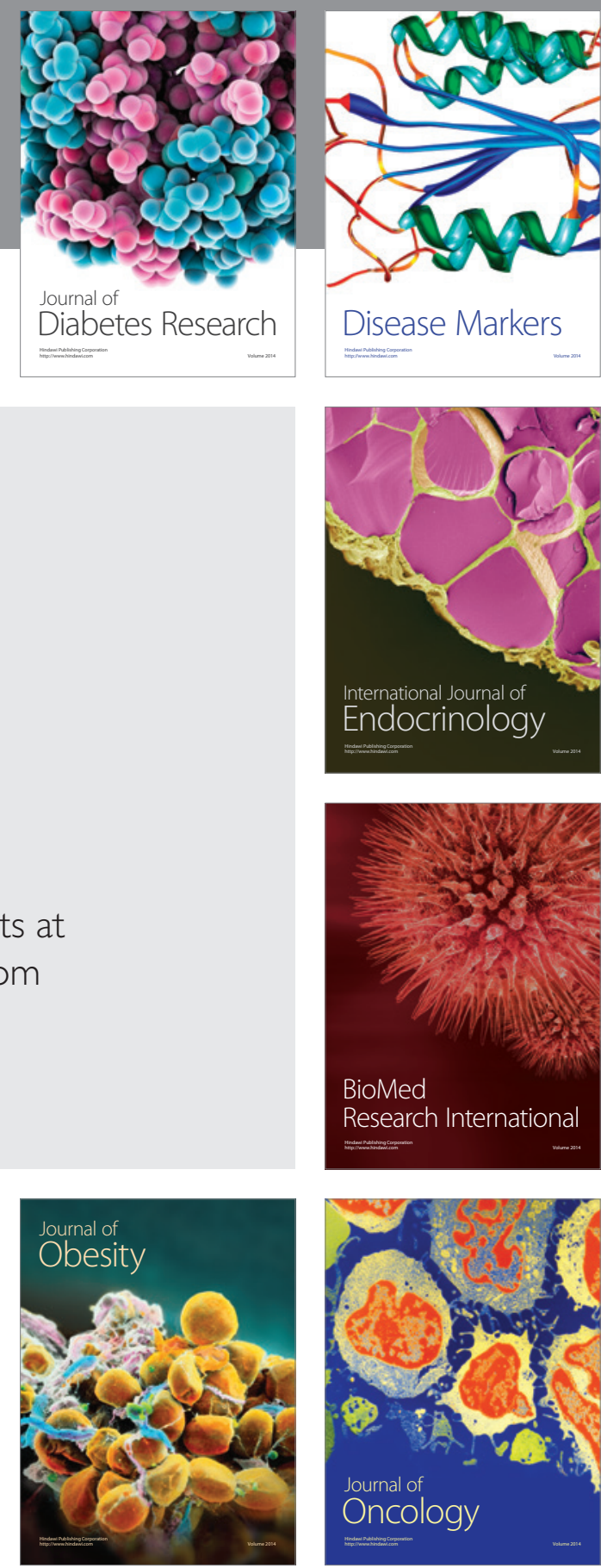

Disease Markers
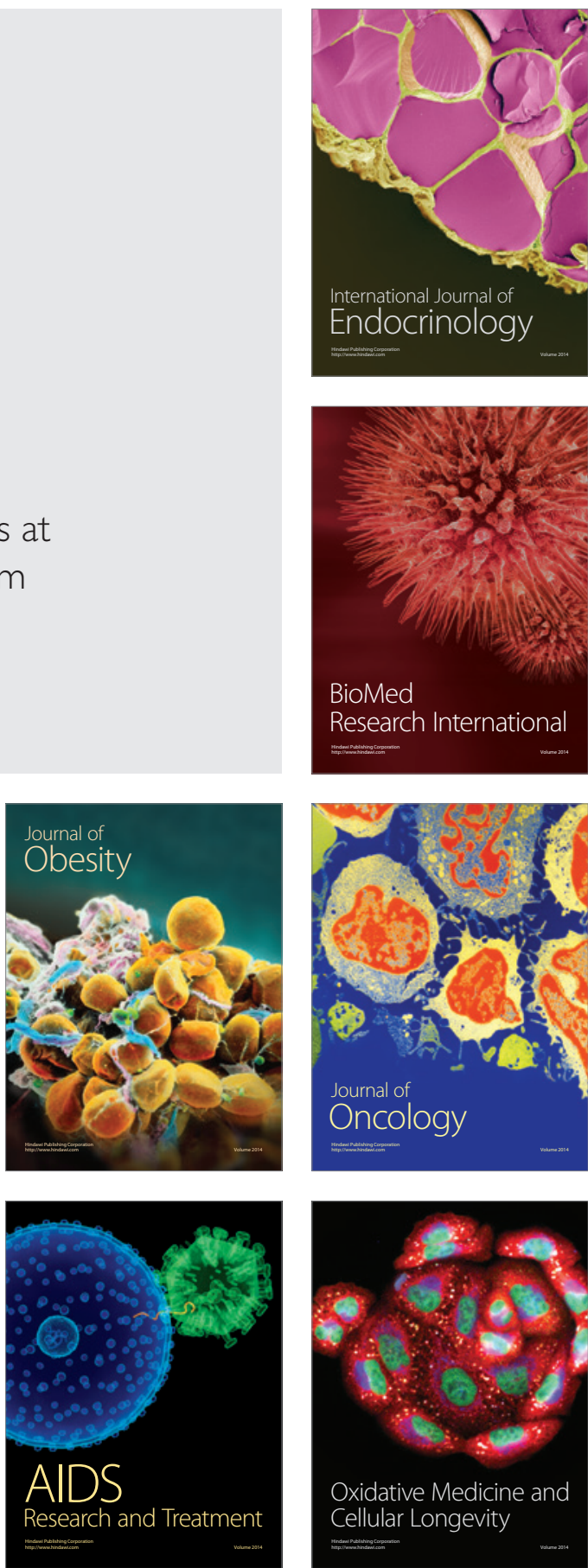